\title{
O CONTRATO DE FRANQUIA E A APLICAÇÃO DO CÓDIGO DE DEFESA DO CONSUMIDOR
}

\author{
THE FRANCHISE CONTRACT AND THE APPLICATION OF THE CONSUMER \\ DEFENSE CODE
}

\author{
Sandra Regina Martini ${ }^{1}$ \\ Fernando Gustavo Knoerr ${ }^{2}$ \\ Fernando Virmond Portela Giovannetti ${ }^{3}$
}

\section{RESUMO}

O setor de franquias responde hoje por 2,4\% (dois vírgula quatro por cento) do Produto Interno Bruto brasileiro e tem apresentado significativo crescimento de faturamento nos últimos anos, bem acima do crescimento médio da economia. A relevância desse setor demonstra a importância do estudo do contrato de franquia. O presente trabalho faz uma análise dos principais aspectos desse instituto, identificando suas principais características, a legislação e

\footnotetext{
${ }^{1}$ Possui graduação em Ciências Sociais pela Universidade do Vale do Rio dos Sinos (1983), mestrado em Educação pela Pontifícia Universidade Católica do Rio Grande do Sul (1997), doutorado em Evoluzione dei Sistemi Giuridici e Nuovi Diritti pela Università Degli Studi di Lecce (2001), Pós-doutorado em Direito (Roma Tre, 2006) e Pósdoutorado em Políticas Públicas (Universidade de Salerno, 2010). Foi Professora titular da Universidade do Vale do Rio dos Sinos, da Scuola Dottorale Internazionale Tullio Ascarelli e professora visitante da Universita Degli Studi Di Salerno. Foi diretora da Escola de Saúde Pública do Rio Grande do Sul (janeiro de 2007 a fevereiro de 2011), foi membro (de janeiro de 2008 a dezembro de 2013) do Conselho Superior da Fundação de Amparo à Pesquisa do Estado do Rio Grande do Sul (FAPERGS). Pesquisadora Produtividade 2 CNPq, Coordenadora do Mestrado em Direitos Humanos e professora do Centro Universitário Ritter dos Reis (UniRitter), professoravisitante no programa de pós-graduação em Direito da UFRGS (PPGD) e no programa de pós-graduação em Direito da UFMS. É avaliadora do Basis do Ministério da Educação e Cultura e do Basis do Instituto Nacional de Estudos e Pesquisas Educacionais Anísio Teixeira. Parecerista ad hoc CNPq e CAPES. Conferencista no Brasil e no exterior. Membro da Rede Iberoamericana de Direito Sanitário.
}

${ }^{2}$ Pós Doutor pela Universidade de Coimbra - Portugal. Doutor e Mestre em Direito do Estado pela Universidade Federal do Paraná. Bacharel em Direito pela Universidade Federal do Paraná. Professor de Direito Administrativo da Escola da Magistratura do Paraná e da Fundação Escola do Ministério Público do Paraná / FEMPAR. É Professor Permanente do Programa de Mestrado em Direito Empresarial e Cidadania do UNICURITIBA. Ex Procurador Federal. Ex Juiz do TRE/PR. Advogado Sênior do Escritório Séllos-Knoerr Sociedade de Advogados. ${ }^{3}$ Mestrando em Direito Empresarial e Cidadania pelo UNICURITIBA. Graduado em Direito pela Faculdade de Direito da Universidade Federal do Paraná. 
os princípios que norteiam seu funcionamento, as diversas modalidades de franquias e suas principais classificações, para ao final realizar uma análise sobre as diversas relações jurídicas existentes, tanto entre franqueadores e franqueados, como entre estes e os consumidores, com o intuito de descobrir se é possível e em quais situações aplicar os princípios e dispositivos legais pertencentes à legislação consumerista.

PALAVRAS-CHAVE: Franquias. Características. Direito do Consumidor.

\begin{abstract}
The franchise sector now accounts for $2.4 \%$ (two point four percent) of the Brazilian Gross Domestic Product and has shown significant growth in revenues in recent years, well above the average growth of the economy. The relevance of this sector demonstrates the importance of franchise agreement study. The present work analyzes the main aspects of this institute, identifying its main characteristics, the legislation and the principles that guide its operation, the different types of franchises and their main classifications, in order to carry out an analysis of the different legal relationships, both between franchisors and franchisees, as well as between consumers and franchisees, to find out if it is possible and in what situations to apply the principles and legal provisions pertaining to consumer legislation.
\end{abstract}

KEYWORDS: Franchises. Features. Consumer Law

\title{
1. INTRODUÇÃO
}

O surgimento do franchising ocorreu nos Estados Unidos da América, no final do século XIX, quando a indústria Singer Sewing Machine Company resolveu expandir suas operações mediante o credenciamento de agentes em diversos pontos do território daquele país, cedendolhes a utilização da marca, publicidade, técnica de vendas, know how e fornecendo-lhes produtos, conforme aponta Marcelo M. Bertoldi. ${ }^{4}$

\footnotetext{
4 BERTOLDI, Marcelo M.; RIBEIRO, Marcia Carla Pereira. Curso avançado de direito comercial. 8 ed. rev., atual. e ampl. São Paulo: Revista dos Tribunais, 2014, p. 851.
} 
Teria surgido, portanto, como consequência da impossibilidade de os industriais nortistas expandirem as suas atividades para o oeste e o sul do país mediante atuação direta e capitais próprios, de modo que, com o franqueamento da atividade, permitiram que comerciantes locais investissem seus capitais na comercialização de produtos que ostentavam marcas já prestigiadas e reconhecidas pelos consumidores. ${ }^{5}$

No Brasil a história do franchising se iniciou em 1960 através da escola de idiomas Yazigi e na década seguinte com a instalação da primeira loja Mc Donald’s no país.

Trata-se, portanto, de um mecanismo utilizado por empresários para difundir seus negócios, levando seus produtos e serviços para diversas regiões, sem a necessidade de fazer pesados investimentos ou constituir filiais.

Marcelo M. Bertoldi ensina que:

\begin{abstract}
A exemplo dos contratos de distribuição, representação comercial, mandato, comissão e concessão, a franquia tem como função econômica a distribuição de produtos e serviços, distinguindo-se daqueles pelo fato de tratar-se de contrato que contempla necessariamente a concessão temporária, por parte do franqueador, de uso de marca ou patente, englobando, ainda, na maioria das vezes, a transferência de know-how, assessoria técnica, mercadológica e administrativa do negócio, mediante a observação de práticas padronizadas. ${ }^{6}$
\end{abstract}

Ou seja, ao contrário dos demais contratos de colaboração, na franquia, além de comercializar produtos ou serviços do franqueador, o franqueado adota seu modelo de organização e apresentação do negócio, criando uma identidade tão grande com aquele que ao público em geral muitas vezes é impossível perceber que se trata de uma franquia e não de uma filial aberta pelo próprio dono da empresa franqueada.

Dentre as vantagens do contrato de franquia para o franqueador, está a expansão da rede e exploração de novos mercados sem a necessidade de investimentos tão grandes como os que teria se o fizesse por si só, o fato de que sua marca passa a atingir um maior número de consumidores, obtendo uma maior valorização, gerando ainda um barateamento dos custos,

\footnotetext{
${ }^{5}$ NEGRÃO, Ricardo. Manual de direito comercial e de empresa: títulos de crédito e contratos empresariais. 3 ed. São Paulo: Saraiva, 2012, p. 307.

${ }^{6}$ Obra citada, p. 851-852.
} 
posto que uma maior demanda do produto possibilitará uma melhor negociação com os fornecedores, entre outras.

Para o franqueado, a grande vantagem é a possibilidade de se servir do prestígio de um produto ou serviço já consagrado e de renome, bem como de utilizar-se de um sistema de vendas, de fabricação ou de prestação de serviços já testado e aprovado pelo mercado, o que contribui para reduzir de forma significativa os riscos que geralmente envolvem o início de uma nova empresa.

O consumidor também é beneficiado, porque a parceria entre franqueador e franqueado lhe garante acesso a um maior número de pontos de venda, propicia aumento da qualidade dos bens ou serviços prestados e reduz o preço.

Em relatório elaborado pelo Ministério da Indústria, Comércio Exterior e Serviços no ano de $2005^{7}$ são apontadas vantagens diretas até para o próprio Estado, posto que do ponto de vista fiscal, ainda que indiretamente, essa atividade força a uma maior transparência no faturamento das empresas, aumentando a base de cálculo para fins de apuração de impostos.

Como desvantagens, Ricardo Negrão ${ }^{8}$ aponta a possibilidade de estragos na imagem de uma marca pelo gerenciamento desastroso do franqueador ou mesmo de um dos franqueados - ex.: numa rede de alimentos, a falta de higiene num estabelecimento pode prejudicar a imagem de todos os outros franqueados; a falência do franqueador opera um desastre financeiro por efeito dominó; uma notícia desabonadora sobre um produto afeta interesses de inúmeros empresários autorizados a distribuí-lo etc.

No Brasil, no ano de 2017, foram contabilizados 146.134 unidades franqueadas, segundo relatório apresentado pela Associação Brasileira de Franchising - $\mathrm{ABF}^{9}$, gerando um total de 1.193.568 empregos. As áreas que apresentaram os maiores faturamentos foram a da alimentação ( $\mathrm{R} \$ 42,816$ bilhões), saúde, beleza e bem estar ( $\mathrm{R} \$ 30,021$ bilhões), serviços e outros negócios ( $\mathrm{R} \$ 22,921$ bilhões), hotelaria e turismo ( $\mathrm{R} \$ 11,251$ bilhões) e serviços educacionais ( $\mathrm{R} \$ 10,839$ bilhões).

\footnotetext{
7 Disponível em <http://investimentos.mdic.gov.br/public/arquivo/arq1273166274.pdf>.

8 Obra citada, p. 309.

9 Disponível em <https:/www.abf.com.br/wp-content/uploads/2018/03/Desempenho-do-Franchising-2017.pdf>
} 
Atualmente, conforme divulgado pelo Presidente da $\mathrm{ABF}^{10}$, o setor de franquias é responsável por 2,4\% (dois vírgula quatro por cento) do Produto Interno Bruto brasileiro e tem apresentado significativo crescimento de faturamento nos últimos anos, tendo em diversas oportunidades ultrapassado a marca de $10 \%$ (dez por cento) de crescimento anual, sendo que nos últimos 3 (três) anos, a despeito da forte crise que atingiu a economia brasileira, o crescimento anual ficou sempre na faixa dos $8 \%$ (oito por cento), conforme o mesmo relatório realizado pela $\mathrm{ABF}$.

Destacada a importância do tema, analisaremos, no presente trabalho, as principais características do contrato de franquia bem como a relação existente entre franqueador, franqueados e entre estes e os consumidores finais dos produtos ou serviços oferecidos, para então analisarmos em quais dessas relações jurídicas é possível a aplicação da legislação protetiva do consumidor.

\title{
2. CONCEITO, CARACTERÍSTICAS E TRATAMENTO LEGAL
}

\author{
Segundo o Dicionário Houaiss, franquia é
}

\begin{abstract}
a relação comercial em que uma pessoa física ou jurídica (o franqueador), titular de marca registrada, patente ou registro de propriedade industrial, concede a outra (o franqueado) licença para a utilização (em atividade de comércio, indústria ou serviços) de sua marca, bem como de seu processo de produção, seus produtos e/ou seu sistema de negócios, mediante o pagamento de royalties e o cumprimento de determinadas condições.
\end{abstract}

Complementando essa definição, Denis Borges Barbosa ${ }^{11}$ esclarece que a franquia é um tipo de negócio jurídico de fundo tecnológico que importa na padronização do aviamento de várias empresas independentes entre si, não necessariamente vinculadas por laços societários diretos ou indiretos - a peculiaridade desse contrato estaria na multiplicação da rede, o que o torna distinto de um contrato de know how somado a uma licença de patentes.

10 Disponível em: <http://economia.ig.com.br/2017-06-21/setor-franquias-abf.html>.

11 BARBOSA, Denis Boges. Franchising. Disponível em <http://www.nbb.com.br/pub/ societario02.pdf>. 
O autor esclarece que a relação entre os envolvidos se constrói tão estreitamente que pouco falta para se completar a unidade empresarial: o contrato via de regra inclui obrigação de exclusividade recíproca - o franqueado só pode comercializar os produtos ou serviços contratados com o franqueador, ao passo que este só pode fornecer os produtos ou autorizar o uso da marca para aquele no espaço geográfico avençado ou, ao menos, dar-lhe preferência.

Tanto é assim que, conforme aponta Ana Carolina Devito Dearo Zanetti ${ }^{12}$, dentre os contratos de distribuição, o contrato de franquia é "aquele em que a integração entre as partes se dá no grau máximo e no qual a cooperação entre empresas independentes assume contornos mais estreitos”, de modo que a identidade de sinais e da apresentação exterior é capaz de gerar nos consumidores a convicção de se tratar do próprio produtor ou de uma filial.

Essa integração decorre também de uma maior intromissão do franqueador na atividade do franqueado, através de cláusulas que obrigam este a fornecer periodicamente demonstrativos financeiros e dados sobre o movimento da unidade, ou que autorizam o franqueador a inspecionar os estabelecimentos dos franqueados a fim de manter a qualidade dos serviços prestados e preservar a integridade dos padrões do sistema de franquias.

A Lei 8.955, de 15 de dezembro de 1994 (Lei de Franquia Empresarial - LEF), prevê um tratamento mínimo à matéria, mais preocupado em garantir a transparência das relações entre franqueadores e franqueados do que em regulamentar a forma como o contrato será redigido ou impor cláusulas obrigatórias, prevalecendo, assim, nesse aspecto, a liberdade dos contratantes, o que possibilita que a franquia assuma formas e características diferentes a depender do setor, do negócio e das partes envolvidas.

Em seu artigo $2^{\circ}$, oferece um conceito para a franquia, a saber:

Franquia empresarial é o sistema pelo qual um franqueador cede ao franqueado o direito de uso de marca ou patente, associado ao direito de distribuição exclusiva ou semi-exclusiva de produtos ou serviços e, eventualmente, também ao direito de uso de tecnologia de implantação e administração de negócio ou sistema operacional desenvolvidos ou detidos pelo franqueador, mediante remuneração direta ou indireta, sem que, no entanto, fique caracterizado vínculo empregatício.

12 ZANETTI, Ana Carolina Devito Dearo. Contrato de ditribuição: o inadimplemento recíproco. São Paulo: Atlas, 2015, p. 44. 
Vê-se, assim, que o franqueador, de forma obrigatória, continuada e sucessiva, oferecerá licença de uso de direitos de propriedade industrial, além de distribuição exclusiva ou semi-exclusiva de produtos ou serviços, sendo ainda facultativo o oferecimento de serviços de tecnologia na implantação, na administração da empresa e de sistema operacional adequado à organização da atividade, ao passo que o franqueado, em contraprestação, além de obrigar-se a respeitar as regras fixadas pelo franqueador durante o período de vigência da franquia (ou até mesmo após sua vigência, nos casos que envolverem sigilo, por exemplo), deve pagar remuneração ao franqueador - os royalties.

A lei não trata de especificidades do contrato, motivo pelo qual a doutrina o classifica como contrato atípico ${ }^{13}$, tendo as partes liberdade para estipular as cláusulas e condições que entenderem necessárias, procurando apenas assegurar ao franqueado o amplo acesso às informações indispensáveis para analisar a conveniência de participar do negócio.

Conforme aponta Luciano Benetti Timm ${ }^{14}$, um ponto de destaque acerca da regulamentação dos contratos de franquia é que a maioria das jurisdições regula a matéria visando proteger o franqueado, por ser ele a parte mais fraca na relação.

Assim, o que a lei brasileira determina é que o franqueador deve elaborar uma Circular de Oferta de Franquia - COF que deve ser entregue ao candidato a franqueado no mínimo 10 (dez) dias antes da assinatura do contrato ou do pré-contrato ou ainda do pagamento de qualquer tipo de taxa pelo franqueado ao franqueador ou a terceiros ligados a ele, determinação que, descumprida, pode ensejar a anulação do contrato e a restituição dos valores pagos $\left(\operatorname{art.} 4^{\circ}\right)$.

Corroborando com a necessidade de que todos os dados necessários sejam oferecidos ao interessado em obter a franquia, a lei estabelece um rol mínimo de informações que devem estar contidas na $\mathrm{COF}$, a saber:

Art. $3^{\circ}$ Sempre que o franqueador tiver interesse na implantação de sistema de franquia empresarial, deverá fornecer ao interessado em tornar-se franqueado

13 Conforme ensina Fábio Ulhoa Coelho: "a lei brasileira sobre franquias não confere tipicidade ao contrato: prevalecem entre franqueador e franqueado as condições, termos, encargos, garantias e obrigações exclusivamente previstos no instrumento contratual entre eles firmado" (Curso de Direito Comercial, 7. ed. São Paulo: Saraiva, 2003, v. 1, p. 126 .

14 TIMM, Luciano Benetti; RIBEIRO, Rafael Pellegrini; ESTRELLA, Angela T. Gobbi. Direito Comercial Internacional. Rio de Janeiro: FGV, 2009, p. 96. 
uma circular de oferta de franquia, por escrito e em linguagem clara e acessível, contendo obrigatoriamente as seguintes informações:

I - histórico resumido, forma societária e nome completo ou razão social do franqueador e de todas as empresas a que esteja diretamente ligado, bem como os respectivos nomes de fantasia e endereços;

II - balanços e demonstrações financeiras da empresa franqueadora relativos aos dois últimos exercícios;

III - indicação precisa de todas as pendências judiciais em que estejam envolvidos o franqueador, as empresas controladoras e titulares de marcas, patentes e direitos autorais relativos à operação, e seus subfranqueadores, questionando especificamente o sistema da franquia ou que possam diretamente vir a impossibilitar o funcionamento da franquia;

IV - descrição detalhada da franquia, descrição geral do negócio e das atividades que serão desempenhadas pelo franqueado;

$\mathrm{V}$ - perfil do franqueado ideal no que se refere a experiência anterior, nível de escolaridade e outras características que deve ter, obrigatória ou preferencialmente;

VI - requisitos quanto ao envolvimento direto do franqueado na operação e na administração do negócio;

VII - especificações quanto ao:

a) total estimado do investimento inicial necessário à aquisição, implantação e entrada em operação da franquia;

b) valor da taxa inicial de filiação ou taxa de franquia e de caução; e

c) valor estimado das instalações, equipamentos e do estoque inicial e suas condições de pagamento;

VIII - informações claras quanto a taxas periódicas e outros valores a serem pagos pelo franqueado ao franqueador ou a terceiros por este indicados, detalhando as respectivas bases de cálculo e o que as mesmas remuneram ou o fim a que se destinam, indicando, especificamente, o seguinte:

a) remuneração periódica pelo uso do sistema, da marca ou em troca dos serviços efetivamente prestados pelo franqueador ao franqueado (royalties);

b) aluguel de equipamentos ou ponto comercial;

c) taxa de publicidade ou semelhante;

d) seguro mínimo; e

e) outros valores devidos ao franqueador ou a terceiros que a ele sejam ligados; IX - relação completa de todos os franqueados, subfranqueados e subfranqueadores da rede, bem como dos que se desligaram nos últimos doze meses, com nome, endereço e telefone;

$\mathrm{X}$ - em relação ao território, deve ser especificado o seguinte:

a) se é garantida ao franqueado exclusividade ou preferência sobre determinado território de atuação e, caso positivo, em que condições o faz; e b) possibilidade de o franqueado realizar vendas ou prestar serviços fora de seu território ou realizar exportações;

XI - informações claras e detalhadas quanto à obrigação do franqueado de adquirir quaisquer bens, serviços ou insumos necessários à implantação, operação ou administração de sua franquia, apenas de fornecedores indicados e aprovados pelo franqueador, oferecendo ao franqueado relação completa desses fornecedores;

XII - indicação do que é efetivamente oferecido ao franqueado pelo franqueador, no que se refere a:

a) supervisão de rede;

b) serviços de orientação e outros prestados ao franqueado;

c) treinamento do franqueado, especificando duração, conteúdo e custos;

d) treinamento dos funcionários do franqueado;

e) manuais de franquia;

f) auxílio na análise e escolha do ponto onde será instalada a franquia; e g) layout e padrões arquitetônicos nas instalações do franqueado;

XIII - situação perante o Instituto Nacional de Propriedade Industrial - (INPI) das marcas ou patentes cujo uso estará sendo autorizado pelo franqueador; 
XIV - situação do franqueado, após a expiração do contrato de franquia, em relação a:

a) know how ou segredo de indústria a que venha a ter acesso em função da franquia; e

b) implantação de atividade concorrente da atividade do franqueador;

XV - modelo do contrato-padrão e, se for o caso, também do pré-contratopadrão de franquia adotado pelo franqueador, com texto completo, inclusive dos respectivos anexos e prazo de validade.

Conforme explica Ricardo Negrão ${ }^{15}$, a COF pode ser dividida em cinco grupos principais, correspondentes a cinco deveres de informação a serem prestados pelo franqueador: 1) dever de informação sobre a pessoa do franqueador e sua rede, relativa à imagem e realidade financeira da franqueadora (incisos I, II, III e IX); 2) dever de identificação integral do objeto do contrato (incisos IV, XII e XIII); 3) dever de informação sobre a qualificação exigida do franqueado: características e comportamentos esperados dele (incisos V, VI e XIV); 4) dever de informação sobre os encargos contratuais (incisos VII, VIII e XI); e 5) dever de explicar a extensão territorial e o regime de exclusividade (inciso X).

$\mathrm{O}$ art. $6^{\circ}$ da Lei 8.955/94 ainda estabelece que "o contrato de franquia deve ser sempre escrito e assinado na presença de 2 (duas) testemunhas e terá validade independentemente de ser levado a registro perante cartório ou órgão público”. Não obstante, o art. 211 do Código de Propriedade Industrial - Lei n9.279/96 - estabelece o registro dos contratos de franquia junto ao Instituto Nacional da Propriedade Industrial - INPI como condição de oponibilidade dele a terceiros.

\section{MODALIDADES DE FRANQUIAS}

Uma das classificações utilizadas pela doutrina, conforme aponta Marcelo M. Bertoldi $^{16}$, leva em conta a atividade desenvolvida pelo franqueador para a implantação do sistema, dividindo a franquia em de serviços, de produção, de distribuição, de indústria e mista.

Será de serviços a franquia que ofereça ao franqueado uma forma original de prestação de serviços a serem oferecidos à sua clientela, mediante a obediência a padrões determinados, como ocorre com cursos de inglês, hotéis, locadoras de veículos etc.

\footnotetext{
15 Obra citada, p. 320.

16 Obra citada, p. 953.
} 
$\mathrm{Na}$ franquia de produção, o franqueador produz os produtos que serão comercializados pela rede de franqueados mediante a utilização de uma ou várias marcas reconhecidas no mercado, tendo como exemplo as lojas de grife.

Já a franquia de distribuição caracteriza-se pela escolha, pelo franqueador, de determinados produtos fabricados por terceiros que serão distribuídos pela rede de franqueados.

A franquia de indústria ocorre quando o franqueador disponibiliza ao franqueado toda uma série de informações (tecnologia e know-how) necessárias para que tenha ele condições de industrializar a distribuir determinada gama de produtos, sob sua supervisão e nos termos em que ficar determinado pelo contrato.

Por fim, será mista a que venha a combinar duas ou mais formas acima mencionadas.

Outra classificação, utilizada pela IFA - International Franchise Association, distingue dois tipos de franquia, a de distribuição de produtos (product franchises) e a de formato negocial (business format franchise), sendo que naquela o franqueador disponibiliza suas licenças de propriedade industrial (tendo como exemplos a Pepsi, a Exxon, e a Ford Motor Company), enquanto que nesta o uso da licença inclui um método completo de condução da atividade empresarial (exemplos: franquias de fast food, locadoras de automóveis etc.).

Essa classificação, sobretudo quanto à primeira modalidade, traz a dificuldade em demarcar esse tipo de franquia de outros contratos, como o de concessão empresarial.

Outra modalidade de franquia é a master franchisee, ou franquia mestre, que corresponde a uma forma de alavancagem do franqueador a mercados onde ele não tem acesso. Trata-se de uma modalidade de franquia múltipla que difere da unitária porque nesta há uma relação direta e imediata entre franqueador e franqueado, enquanto que naquela o franqueado tem o direito de subfranquear o negócio a terceiros, dentro de determinado território, ficando assim numa dupla posição: a de franqueado em relação ao titular da marca e a de franqueador em relação às unidades franqueadas. 
Pedro Marcos Nunes Barbosa ${ }^{17}$ esclarece que essa modalidade de franquia é recomendável, por exemplo, para empresas estrangeiras que desejem abrir franquias no território nacional, podendo assim escolher um franqueado mestre e delegar a ele o direito de subfranquear suas operações no país, o que caracteriza uma franquia indireta, bastante comum para multinacionais.

\section{A APLICAÇÃ̃ DA LEGISLAÇÃO CONSUMERISTA ÀS RELAÇÕES JURÍDICAS DECORRENTES DO CONTRATO DE FRANQUIA}

A aplicação da legislação protetiva do direito do consumidor, no que se refere ao sistema de franquias, pode ser estudada tomando-se por base três relações jurídicas diversas.

Em primeiro lugar, há quem defenda a aplicação do Código de Defesa do Consumidor - CDC na relação entre o franqueado e o franqueador nos casos em que for manifesta a desigualdade econômica entre os envolvidos, posto que caracterizada a hipossuficiência do franqueado se comparado ao franqueador.

É comum, realmente, a existência de situações em que o franqueador consiste numa megaempresa de porte nacional ou até mesmo internacional, ao passo que o franqueado se apresenta como uma micro ou pequena empresa, com pouca ou nenhuma independência ou margem de negociação com aquele, encontrando-se em evidente submissão aos ditames do franqueador.

Isso, em que pese demonstrar a hipossuficiência de uma das partes, não é o suficiente para ensejar a aplicação do CDC, que não ter por objetivo promover o equilíbrio em toda e qualquer relação jurídica em que constate uma desigualdade econômica entre as partes, mas apenas nos casos em que tal relação puder ser considerada como de consumo.

17 BARBOSA, Pedro Marcos Nunes. Oferecimento de franquias por empresas estrangeiras. Disponível em <http://www.nbb.com.br/pub/propriedade21.pdf >. 
Nos termos de seus artigos primeiro e segundo, o referido código estabelece normas de proteção e defesa do consumidor, considerando-se como tal "toda pessoa física ou jurídica que adquire ou utiliza produto ou serviço como destinatário final”, de modo que o franqueado, como participa dessa relação jurídica visando o lucro através da comercialização dos produtos ou serviços do franqueador, não consiste em destinatário final, afastando a aplicação desse diploma.

Nesse sentido, vale transcrever a lição de Cláudio Roberto Barbosa ${ }^{18}$ :

Se o franqueador presta serviços e precisa - para atingir seus objetivos - ajudar o franqueado a manter sua atividade de forma organizada (ainda que vise preservar, com isso, as características que o consumidor final espera da atividade franqueada) esta ingerência na atividade do franqueado transfigurase, para alguns, como autoridade. Neste sentido, não é raro pessoas considerarem tal aspecto como uma posição superior do franqueador sobre o franqueado. Se tal preponderância não chega a caracterizar uma relação de consumo, certamente apresenta algumas similaridades, particularmente a dependência e alguns aspectos comerciais antagônicos o que acarreta um grande número de decisões sobre o tema.

A utilização da imagem da empresa ajuda a consolidar o contrato de franquia como empresarial e organizacional, particularmente, reforçando a posição jurisprudencial de que não existe uma relação consumerista entre franqueador e franqueado. A jurisprudência, ao contrário, afirma que "[o] contrato de franquia, por sua natureza, não está sujeito ao âmbito de incidência da Lei $n^{\circ}$ $8.078 / 1990$, eis que o franqueado não é consumidor de produtos ou serviços da franqueadora, mas aquele que os comercializa junto a terceiros, estes sim, os destinatários finais" (STJ. REsp. 632958/AL, Rel. Ministro Aldir Passarinho Junior, Quarta Turma, julgado em 04/03/2010, DJE 29/03/2010).

Da mesma forma, Danielle de Oliveira Duarte ${ }^{19}$ conclui pela não aplicação do CDC posto que o contrato assinado pelo franqueado representa um negócio jurídico entre empresários, estando assim regulamentado pelo Código Civil e pela Lei $n^{\circ}$ 8.955/94 que é específica do contrato de franquias.

Outra relação jurídica que pode decorrer da atividade decorrente da franquia é aquela que existe entre os franqueados e aqueles indivíduos que adquirem seus produtos os serviços.

${ }^{18}$ BARBOSA, Claudio Roberto. O contrato de franquia e sua dimensão empresarial vista pela jurisprudência. In: Contratos empresariais interpretados pelos Tribunais. São Paulo: Quartier Latin, 2014, p. 145.

19 DUARTE, Danielle de Oliveira. Contrato de franquia e suas relações jurídicas. Disponíve em: <https://www.direitonet.com.br/artigos/exibir/10027/Contrato-de-franquia-e-suas-relacoes-juridicas $>$. Acesso em $11 / 12 / 2018$. 
Aqui, tem-se a relação de consumo por excelência, eis que de um lado encontra-se o consumidor, aquele que é o destinatário final, e do outro lado o fornecedor do produto ou serviço objeto da franquia, ambos perfeitamente caracterizados.

Por fim, a terceira relação é aquela porventura existente entre o consumidor final e o fraqueador da atividade.

Como já bem destacado, a relação jurídica direta do franqueador é com o franqueado, disciplinada através da circular de oferta de franquia e do subsequente contrato realizado entre as partes - não se envolve, o franqueador, a princípio, com a prestação direta do serviço à coletividade, o que é realizado apenas indiretamente, através do franqueado.

Cabe, então, analisar a situação do franqueador em face dos consumidores finais do produto ou serviço objeto da franquia, para o que se deve ter em mente qual a extensão do conceito de fornecedor ou prestador de serviços para fins de aplicação da lei consumerista.

$\mathrm{O}$ artigo terceiro e seus respectivos parágrafos do referido diploma assim estabelece:

Art. $3^{\circ}$ Fornecedor é toda pessoa física ou jurídica, pública ou privada, nacional ou estrangeira, bem como os entes despersonalizados, que desenvolvem atividade de produção, montagem, criação, construção, transformação, importação, exportação, distribuição ou comercialização de produtos ou prestação de serviços.

$\S 1^{\circ}$ Produto é qualquer bem, móvel ou imóvel, material ou imaterial.

$\S 2^{\circ}$ Serviço é qualquer atividade fornecida no mercado de consumo, mediante remuneração, inclusive as de natureza bancária, financeira, de crédito e securitária, salvo as decorrentes das relações de caráter trabalhista

Nesse sentido, considerando-se o franqueador como fornecedor, sua responsabilidade será sempre objetiva perante o consumidor, tendo a obrigação de indenizar sem a necessidade de ser demonstrada sua culpa.

É uma situação de fácil constatação nas franquias de produção, posto que, embora o franqueado lide diretamente com o consumidor, sua atividade se assemelha à de um 
revendedor do produto do franqueador. É o que ocorre, por exemplo, quando os franqueados se limitam a adquirir do fabricante os produtos com a sua marca e revendê-los.

Não há como se afastar a responsabilidade do franqueador nesses casos já que inequivocamente assume a posição de fabricante, ou seja, de fornecedor do produto - inclusive, em havendo falha no produto, responderá ao próprio franqueado pelos prejuízos que este tiver que suportar, em ação de regresso.

Situação que pode gerar alguma dúvida ocorre em franquias nas quais o franqueado obtenha do franqueador o know-how necessário para a prestação de determinado serviço e o faça por si mesmo, sem a utilização de produtos ou pessoal do franqueador, e, no desempenho dessa atividade, desvie-se dos padrões os quais se comprometeu seguir e por conta disso lese o direito de algum consumidor.

Nesse caso, seria possível que o franqueador pretendesse se esquivar de uma responsabilidade perante o consumidor, alegando a falta de qualquer culpa sua no fato que gerou aquele dano, apontando assim para uma responsabilização única e exclusiva do franqueado que tanto lesionou o cliente como descumpriu cláusulas contratuais do contrato de franquia.

Não há como se esquecer, todavia, que para o consumidor o franqueado nada mais é do que uma extensão do franqueador. Não é com aquele que o consumidor procurou contratar, não foram seus serviços que procurou adquirir, mas sim os serviços oferecidos por este através de sua cadeia de franquias. Muitas vezes o consumidor sequer sabe que está a tratar com uma franquia ou uma filial - e é essa a grande vantagem desse tipo de negócio: fazer parecer, aos olhos dos consumidores, que se trata de uma única empresa, desempenhando sempre aquela conhecida atividade com aquela qualidade também já conhecida.

Assim, ao mesmo tempo que o franqueador se beneficia dessa rede de franquias, podendo potencializar a expansão de sua atividade para mercados que de outra forma não teria acesso, torna-se também responsável por toda e qualquer atuação dos franqueados em seu nome. 
Dessa forma, ainda nesses casos em que o dano ao consumidor decorreu de uma falha no serviço prestado pelo franqueado, contrariando as instruções do franqueador, também este será responsável perante o consumidor, de forma solidária àquele, podendo resguardar seu direito em face daquele apenas mediante posterior ação de regresso.

Daí a importância de que o franqueador discipline de forma pormenorizada a prestação dos serviços por sua rede de franquias e mantenha uma supervisão eficiente e precisa do desempenho de cada uma delas.

É esse o entendimento consolidado no E. Superior Tribunal de Justiça, conforme publicado em seu Informativo ${ }^{\circ} 569$ :

DIREITO DO CONSUMIDOR. RESPONSABILIZAÇÃO CIVIL DE FRANQUEADORA EM FACE DE CONSUMIDOR. A franqueadora pode ser solidariamente responsabilizada por eventuais danos causados a consumidor por franqueada. No contrato de franquia empresarial, estabelecese um vínculo associativo entre sociedades empresárias distintas, o qual, conforme a doutrina, caracteriza-se pelo "uso necessário de bens intelectuais do franqueador (franchisor) e a participação no aviamento do franqueado (franchise)". Dessa forma, verifica-se, novamente com base na doutrina, que o contrato de franquia tem relevância apenas na estrita esfera das empresas contratantes, traduzindo uma clássica obrigação contratual inter partes. Ademais, o STJ já decidiu por afastar a incidência do CDC para a disciplina da relação contratual entre franqueador e franqueado (AgRg no REsp 1.193.293-SP, Terceira Turma, DJe 11/12/2012; e AgRg no REsp 1.336.491SP, Quarta Turma, DJe 13/12/2012). Aos olhos do consumidor, entretanto, trata-se de mera intermediação ou revenda de bens ou serviços do franqueador, que é fornecedor no mercado de consumo, ainda que de bens imateriais. Aliás, essa arquitetura comercial - na qual o consumidor tem acesso a produtos vinculados a uma empresa terceira, estranha à relação contratual diretamente estabelecida entre consumidor e vendedor - não é novidade no cenário consumerista e, além disso, não ocorre apenas nos contratos de franquia. Desse modo, extraindo-se dos arts. 14 e 18 do CDC a responsabilização solidária por eventuais defeitos ou vícios de todos que participem da introdução do produto ou serviço no mercado (REsp 1.058.221-PR, Terceira Turma, DJe 14/10/2011; e REsp 1.309.981-SP, Quarta Turma, DJe 17/12/2013) - inclusive daqueles que organizem a cadeia de fornecimento -, as franqueadoras atraem para si responsabilidade solidária pelos danos decorrentes da inadequação dos serviços prestados em razão da franquia, tendo em vista que cabe a elas a organização da cadeia de franqueados do serviço. REsp 1.426.578-SP, Rel. Min. Marco Aurélio Bellizze, julgado em 23/6/2015, DJe 22/9/2015.

Há ainda a possibilidade de o franqueador responder diretamente pelos danos causados sem que seja possível a responsabilização do franqueado, em atuações daquele que atinjam diretamente direitos dos consumidores sem que haja a necessidade de intermédio de alguns dos franqueados. 
Tem-se como exemplo a utilização de campanhas publicitárias que de alguma forma lesem os diretos dos consumidores. Sendo tais campanhas promovidas na mídia pelo franqueador e sob sua responsabilidade, não há como se pretender a responsabilização dos franqueados, que não possuem qualquer participação na divulgação dessas informações.

\section{CONCLUSÃO}

De forma despretensiosa, o presente artigo limitou-se a apresentar, de modo bastante breve e geral, algumas das características que marcaram o sistema de franquias no Brasil.

Como visto, trata-se de forma bastante atraente para a expansão de determinado negócio sem que o empresário precise dispender grandes investimentos e assumir grandes responsabilidades, tais como procura de imóvel adequado, preparação do estabelecimento, contratação, treinamento e controle de funcionários, entre outros, ao passo que oferece ao franqueado a possibilidade de iniciar uma empresa aproveitando-se de um aviamento já existente, ou seja, de prestar uma atividade já conhecida, com uma clientela já formada, aproveitando de métodos já consagrados e do renome do franqueador.

Para os consumidores, no entanto, é indiferente o fato de estarem contratando com um franqueado ou com o próprio franqueador - como visto, muitas vezes eles sequer têm conhecimento se estão diante de uma franquia ou de uma filial.

Assim, da mesma forma que se vale de um método de expansão de seu negócio, o franqueador deve estar preparado para lidar com os riscos daí inerentes, em especial o de possibilitar a terceiros, através desse contrato, agir em seu nome frente aos consumidores, posto que sempre poderá ser responsabilizado perante esses pelos atos praticados por aqueles.

Daí a importância de o contrato prever formas de fiscalização e controle por parte do franqueador sobre as atividades desempenhadas nas franquias, bem como, e principalmente, de que ele efetivamente realize esse controle, tanto para garantir a padronização de sua marca como para evitar o cometimento de ilícitos em seu nome. 


\section{REFERÊNCIAS}

ARAUJO, Alessandra. Quem responde perante os consumidores, o franqueado ou o franqueador? Disponível em: <http://www.administradores.com.br/noticias/ negocios/quemresponde-perante-os-consumidores-o-franqueado-ou-o-franqueador/14592/>. Acesso em 10/12/2018.

BARBOSA, Claudio Roberto. O contrato de franquia e sua dimensão empresarial vista pela jurisprudência. In: Contratos empresariais interpretados pelos Tribunais. São Paulo: Quartier Latin, 2014.

BARBOSA, Denis Boges. Franchising. Disponível em <http://www.nbb.com.br/ pub/societario02.pdf>. Acesso em 17/03/2018.

BARBOSA, Pedro Marcos Nunes. Oferecimento de franquias por empresas estrangeiras. Disponível em <http://www.nbb.com.br/pub/propriedade21.pdf>. Acesso em 17/03/2018.

BERTOLDI, Marcelo M.; RIBEIRO, Marcia Carla Pereira. Curso avançado de direito comercial. 8 ed. rev., atual. e ampl. São Paulo: Revista dos Tribunais, 2014.

BRASIL, Ministério da Indústria, Comércio Exterior e Serviços - MDIC. Descrição do sistema de franquias. Disponível em: <http://investimentos.mdic. gov.br/public/arquivo /arq1273166274.pdf>. Acesso em 18/03/2018.

COELHO, Fabio Ulhoa. Curso de Direito Comercial, v. 1, 7. ed. São Paulo: Saraiva, 2003,

DUARTE, Danielle de Oliveira. Contrato de franquia e suas relações jurídicas. Disponíve em: $\quad<$ https://www.direitonet.com.br/artigos/exibir/10027/Contrato-de-franquia-e-suasrelacoes-juridicas>. Acesso em 11/12/2018. 
FERREIRA, Iverly Antiqueira Dias. A franquia empresarial e a expectativa do consumidor. Disponível em: <https://www.migalhas.com.br/dePeso/16,MI153646, 11049A+franquia+empresarial+e+a+expectativa+do+consumidor $>$. Acesso em 12/12/2018.

GLITZ, Frederico Eduardo Zenedin; ROCHA, Glenyo Cristiano. Quebra antecipada do contrato: uma análise de direito comparado. Revista Juridica, [S.1.], v. 1, n. 46, p. 300-333, jul. 2017. ISSN 2316-753X. Disponível em: <http://revista.unicuritiba.edu.br/index.php/RevJur/article/view/2010/1291>. Acesso em: 14 abr. 2020. doi:http://dx.doi.org/10.21902/revistajur.2316-753X.v1i46.2010.

MARTINS, Ivo Fernando Pereira. Franquia: responsabilidade pelo dano ao consumidor. Disponível em <https://ivofpmartins.com.br/franquia-responsabilidade-pelo-dano-aoconsumidor/>. Acesso em 12/12/2018.

NEGRÃO, Ricardo. Manual de direito comercial e de empresa: títulos de crédito e contratos empresariais. 3 ed. São Paulo: Saraiva, 2012.

TIMM, Luciano Benetti; RIBEIRO, Rafael Pellegrini; ESTRELLA, Angela T. Gobbi. Direito Comercial Internacional. Rio de Janeiro: FGV, 2009.

ZANETTI, Ana Carolina Devito Dearo. Contrato de distribuição: o inadimplemento recíproco. São Paulo: Atlas, 2015. 